\title{
Role of PD1/PDL1 Pathway, and Th17 and Treg Cells in Maternal Tolerance to the Fetus
}

\author{
Sudipta Tripathi ${ }^{1,2}$, Indira Guleria ${ }^{1,2}$
}

\begin{abstract}
Tolerance of the fetus by the maternal immune system is regulated through various mechanisms involving the different immune cells, both in the periphery and locally at the feto-maternal interface. The maternal $\mathrm{T}$ lymphocytes are aware of the paternal fetal antigens and a state of dynamic $\mathrm{T}$ cell homeostasis is maintained in the uterus during gestation, which involves increase in antigen-specific regulatory $\mathrm{T}$ cell (Treg) proliferation, increase in apoptosis of antigen-specific effector T cells, and inhibition of excessive inflammation post successful implantation to ensure tolerance to the fetus. The Tregs play an important role in the maintenance of tolerance during gestation. Recently, the inflammatory Thelper type 17 (Th17) cells are reported to have a role in loss of tolerance to the fetus. The interaction between costimulatory molecule programmed death 1 (PD1) and its ligand PDL1 is known to play a role in regulating both the Tregs and Th17 cells. Here we discuss how

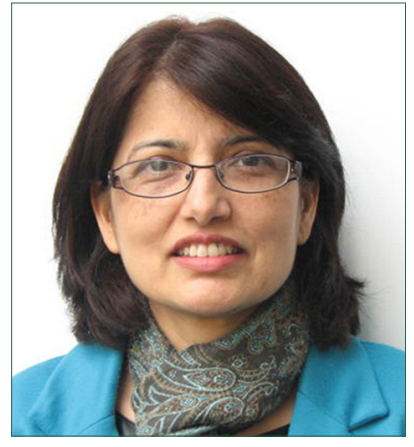

Dr. Indira Guleria the PD1/PDL1 pathway affects these two T cell populations and its role in feto-maternal tolerance. (Biomed J 2015;38:25-31)
\end{abstract}

\section{Key words: feto-maternal tolerance, PD1/PDL1, Th17}

$I^{\prime}$ $\mathrm{t}$ is conventional knowledge that a $\mathrm{T}$ helper type 2 (Th2)-type immunity is essential, dominant, and protective in the context of feto-maternal tolerance. ${ }^{[1-4]}$ In mice, the expression of Th2-type cytokines, interleukin (IL)-4, IL-5, and IL-10, are reported at the feto-maternal interface (FMI). The Th2-type cytokine environment is maintained all throughout the gestation period, whereas interferon gamma (IFN- $\gamma$ ), an inflammatory T helper type 1 (Th1) cytokine, along with IL-11, tumor necrosis factor (TNF), and leukemia inhibitory factor (LIF) are, though essential, are transient and detectable in early pregnancy. ${ }^{[5]}$ Thus, the simplistic concept of good-Th2 type and bad-Th1 type of response has been used to describe the phenomenon of feto-maternal tolerance. However, recurrent spontaneous abortions and preeclampsia are observed and reported in both Th1 and Th2 dominant immunity. Therefore, the Th1/Th2 paradigm does not adequately explain the mechanisms of tolerance at the FMI. ${ }^{[6]}$ Further, identification of novel Th-type populations, namely T helper type 17 (Th17) and regulatory T cells (Tregs), adds more layers of complexity to the paradox of tolerance to the fetus. Both the Th17 and Treg populations have been shown to play a role in modulating the tolerance at the FMI. ${ }^{[7]}$ This review aims to examine the crosstalk between Th17 and Tregs and the role of programmed death 1 (PD1)/PDL1 (ligand of PD1) pathway in induction and maintenance of tolerance at the FMI.

\section{Mechanisms of tolerance at the FMI}

A successful pregnancy is the result of maintenance of tolerance to the fetus by the maternal immune system, as well as protection from other harmful infections. A dysregulated maternal immunity is associated with complications in pregnancy resulting in fetal loss. The immune cells present in the uterus during the period of gestation are tightly regulated and a very fine balance exists between immunity and tolerance at the FMI. A number of different mechanisms are involved in the maintenance of feto-maternal tolerance and have been described and discussed in detail by various

From the ${ }^{1}$ Transplantation Research Center, Boston Children's Hospital and Brigham and Women's Hospital, Boston, USA; ${ }^{2}$ Renal Division, Harvard Medical School, Boston, USA

Received: Jun. 12, 2014; Accepted: Sep. 30, 2014

Correspondence to: Dr. Indira Guleria, Transplantation Research Center, Boston Children's Hospital and Brigham and Women's Hospital, Boston, USA. 300 Longwood Avenue, Boston, MA 02115, USA.

Tel: 1-617-919-2988; Fax: 1-617-732-0129; E-mail: Indira.Guleria@ childrens.harvard.edu

DOI: $10.4103 / 2319-4170.143511$ 
authors. ${ }^{[4,8-12]}$ In this section, we will briefly highlight the mechanisms involving the immune cells, both at the site and in the periphery, that contribute to the maintenance of tolerance at the FMI.

The semi-allogeneic nature of the fetus expressing the paternal antigens is capable of inducing an allogeneic response from the maternal immunity. However, the trophoblast cells in both human and mice lack the expression of major histocompatibility complex (MHC) class II molecules on their surface, and thereby prevent the MHC class II-mediated $\mathrm{T}$ cell response. On the other hand, the trophoblast cells do express low levels of classical MHC class I molecules that makes the fetus prone to attack by the natural killer (NK) cells. ${ }^{[13]}$ The NK cell-mediated lysis of trophoblast cells is prevented by the co-expression of MHC class I molecules and the NK inhibitory receptors that suppress activation of $\mathrm{NK}$ cells, ${ }^{[14]}$ as well as the interactions of NK cells with non-classical MHC class I molecules like HLA-G and HLA-E expressed on the trophoblast. ${ }^{[15]}$ There are also several factors preferentially induced by the trophoblast that create an immunosuppressive microenvironment. Indoleamine 2,3-dioxygenase (IDO) is one such enzyme that exerts a distinct immunosuppressive function together with Tregs, resulting in $\mathrm{T}$ cell anergy and inhibition of proliferation. ${ }^{[16]}$ Another regulatory glycoprotein called glycodelin-A (GdA) is also secreted by the trophoblast cells in response to progesterone, which selectively inhibits Th1 type of cells and shifts the cytokine milieu toward a Th2 type ${ }^{[17,18]} \mathrm{GdA}$ also induces tolerance in dendritic cells. ${ }^{[19]}$ Expression of Fas ligand by the trophoblast cells that can induce apoptosis of activated lymphocytes that express Fas is another mechanism by which tolerance is maintained at the FMI. ${ }^{[20-22]}$ Fas ligand is reported to be expressed by both human and murine trophoblast cells and contribute toward the tolerance of the fetus by the maternal immune system. ${ }^{[23-26]}$

Multiple mechanisms of peripheral tolerance also prevent a maternal alloresponse, as there is evidence to suggest that $\mathrm{T}$ cell awareness of paternal alloantigen exists and maternal alloreactive $\mathrm{T}$ cells persist throughout gestation. ${ }^{[27,28]}$ Tregs are present and have been detected in the human deciduas, ${ }^{[29,30]}$ and are essential for the maintenance of tolerance in allogeneic pregnancy in mice. ${ }^{[31,32]} \mathrm{In}$ humans, an increase in circulatory Tregs has been reported during early pregnancy, which peaks at the second trimester and declines postpartum. ${ }^{[33]}$ In another study, Wegienka et al . also reported an increase of Tregs in the periphery between the prenatal and postpartum period. ${ }^{[34]}$

Fetal antigens are also recognized by the maternal B cells and tolerance to the fetus is achieved by deletion of alloantigen-specific $\mathrm{B}$ cells during gestation, as reported by Ait-Azzouzene et al. ${ }^{[35,36]}$
Negative costimulatory signaling pathways, like CTLA4/B7 and PD1/PDL1, involved in the regulation of effector $\mathrm{T}$ cell activation and proliferation are also known to contribute toward the tolerance of the fetus. Both the CTLA4 and PD1 molecules are expressed on the Tregs and play a role in the suppressive function of these cells.

Polymorphism in the CTLA4 gene is associated with preeclampsia in humans, suggesting an important role of this negative costimulatory molecule in feto-maternal tolerance. ${ }^{\left[{ }^{37]}\right.}$ Decreased expression of CTLA4 is reported in fetal loss in humans. ${ }^{[38,39]}$ Low ratios of CTLA4/CD28 are also associated with fetal loss. ${ }^{[40]}$ In mice, blockade of CD80 (B7.1) and CD86 (B7.2), the ligands for both CD28 and CTLA4, is shown to be protective in abortion-prone allogeneic mating and increases fetal viability. ${ }^{[41]}$ This protective effect of anti-B7 antibody treatment might be due to inhibition of the CD28/B7 signaling, but the authors report an accompanied increase in CTLA4 expression in Tregs. There are also contrasting reports where neither blockade of CTLA4 interferes with the tolerance induction ${ }^{[42]}$ nor blockade of B7.2 has a protective effect on viability of the fetus in mice. ${ }^{[43]}$ The role of CTLA4/B7 pathway in feto-maternal tolerance is summarized here. ${ }^{[44]}$

The PD1/PDL1 pathway, like CTLA4/B7, is a negative regulator of effector $\mathrm{T}$ cell function and is thought to maintain peripheral tolerance. ${ }^{[45]}$ PDL1 is expressed by the fetal cells and interacts with the PD1-expressing maternal cells, like the Tregs or the naïve $\mathrm{T}$ cells, and contributes to the tolerant uterine microenvironment. Blockade of the PD1/PDL1 pathway affects the Treg population and results in fetal loss in mice. ${ }^{[42,43,46]}$

Another costimulatory pathway, namely the ICOS/B7h, is also reported to play a critical role in the maintenance of a tolerogenic environment at the FMI. Blockade of this pathway results in increase in fetal loss by reducing IDO and transforming growth factor beta (TGF $\beta$ ) locally at the FMI and increasing CD8+ T effector cell response in the periphery ${ }^{[47]}$ The role of $\mathrm{B} 7$ family of costimulatory molecules as regulators of feto-maternal tolerance is discussed in detail in the article by Petroff and Perchellet. ${ }^{[48]}$

\section{Tregs and tolerance at the FMI and in the periphery}

Tolerance at the FMI is attributed to various mechanisms involving many different cell types. Dendritic cells (DCs), ${ }^{[49,50]}$ macrophages, ${ }^{[51]}$ and uterine $\mathrm{NK}^{[52]}$ cells are all involved in this complex regulation of tolerance. Current evidence suggests that Tregs also play an important role in this phenomenon, both in the periphery as well as locally at the FMI. ${ }^{[31,32,53,54]}$

The frequency of Tregs is markedly increased in early pregnancy, reaches a peak at mid gestation, and thereafter 
decreases to the non-pregnant levels postpartum. ${ }^{[55]}$ Similar increase in Tregs during pregnancy in humans is also reported. ${ }^{[33,34]}$ Fetal antigen-specific maternal Treg response was reported in a study by Kahn et al. where a selective reduction in male offsprings was observed after in vivo deletion of Tregs. ${ }^{[56]}$ Expansion of Tregs in response to paternal antigens during pregnancy is also reported in allogeneic pregnancy in mice. Both depletion and adoptive transfer of Tregs modulate the rate of resorption. Depletion of Tregs results in an increased rate of resorption and failure in implantation in early pregnancy, as reported by Shima et al..$^{[57]}$ In another study, Yin et al. provide similar evidence of modulation of fetal resorption by Tregs in early pregnancy by adoptive transfer of Tregs expanded in vitro. ${ }^{[58]}$ An increase in the Treg population in the periphery during allogeneic pregnancy ${ }^{[31,32,59]}$ and recognition and tolerance to paternal alloantigens are reported in mice model of allogeneic pregnancy. ${ }^{[60,61]}$

The role of Tregs in maintaining tolerance in human pregnancy is also reported by various groups, ${ }^{[33,62,63]}$ The proportion of peripheral Treg population is reported to be low in patients with unexplained recurrent spontaneous abortions compared to patients with normal pregnancies. ${ }^{[64,65]}$

Hao et al. propose a possible mechanism of Treg expansion at the FMI that is dependent on the production of IDO by the trophoblasts. IDO produces kynurenine that activates the aryl hydrocarbon receptor (AhR) and leads to AhR-dependent Treg cell generation. ${ }^{[66]}$

There is general consensus that Treg population expands in the periphery during gestation in both human and mice. However, there are conflicting reports about the kinetics of Treg levels at different stages of gestation. The role of Tregs in the pathology of preeclampsia in humans is also controversial, with studies reporting decrease in Treg levels in preeclampsia patients and those reporting otherwise. In mice, however, a lower level of Tregs at the local site as well as periphery is associated with fetal loss. All of the above and a more detailed discussion on the role of Tregs in murine and human pregnancies are discussed in the review by Teles et al. ${ }^{[67]}$

The role of Tregs in maintaining tolerance at the periphery and also locally at the FMI during gestation is extensively studied and is well established. ${ }^{[68,69]}$ The recent understanding in Treg plasticity and their conversion to Th17-type cells is important in the context of feto-maternal tolerance and needs to be addressed as more reports of Th17 cell involvement in fetal loss emerge.

\section{Role of Th17 in maintenance of tolerance at the FMI}

The IL-17 secreting inflammatory Th17 cells have been associated with rejection of allografts and abrogation of tolerance. But their role in feto-maternal tolerance is not so well studied. In humans, there are conflicting reports of circulating levels of Th17 cells in the periphery during pregnancy. Low frequencies of Th17 cells are reported in the decidua in comparison to blood during early pregnancy in humans. ${ }^{[70]}$ In women with recurrent spontaneous abortion, serum IL-17 level is reported to be significantly high. ${ }^{[71,72]}$ Increased IL-17 secretion and administration of recombinant IL-17 are reported to increase the rate of resorption in mice.

In a study by Liu et al. conditioned media from trophoblast cells cultured in vitro modulated the peripheral $\mathrm{T}$ lymphocytes to a Th2 type of phenotype and decreased Th1 cytokine production as well as IL-17 production. ${ }^{[73]}$

Wang et al. have shown that Th17 cells increase in patients with recurrent spontaneous abortion that is accompanied by the decrease of Tregs. They also reported a disruption in regulation of Th17 cells by Tregs in these patients. ${ }^{[71,72]} \mathrm{In}$ another study by Wang et al. administration of recombinant IL-17 (rIL-17) was observed to increase the rate of abortion that was accompanied by a decrease in TGF- $\beta$ and IL-10 production in mice. Further, adoptive transfer of Tregs into these mice reversed the effect of rIL-17 administration, ${ }^{[74]}$ suggesting the role of Tregs in controlling the effect of IL-17 or Th17 cells in pregnancy.

The in vivo plasticity of the Th17 cells and their inverse correlation with the Treg population provides an interesting addition to the existing Th1/Th2 paradigm in the context of feto-maternal tolerance. Two cytokines associated with successful pregnancy, IL-4 and IL-6, also play a role in modulating the Th17 cells ${ }^{[75,76]}$ and may point toward a Th cell plasticity between Th1, Th2, and Th17 cell populations, which is beyond the scope of this review. The role of IL-4 in the regulation of Th17 cells has been discussed in detail elsewhere. ${ }^{[77]}$ Having said that, the plasticity of the Th17 cells is their most interesting characteristic and future studies will provide additional dimensions to our understanding of tolerance at the FMI.

\section{PD1/PDL1 pathway and feto-maternal tolerance}

The PD1/PDL1 pathway is one of the major negative costimulatory pathways, along with CTLA4, that regulates $\mathrm{T}$ cell activation and has been shown to play a role in the in vivo plasticity of Th cells, resulting in conversion of Th1 cells to Treg type. ${ }^{[78]}$ The PD1/PDL1 pathway is also thought to maintain peripheral tolerance. ${ }^{[45]}$ The role of this pathway is relevant in the context of feto-maternal tolerance, as PDL1 is expressed on the trophoblast cells of the placenta and PD1 is expressed on the maternal effector and Tregs.

The role of PD1/PDL1 pathway in mediating tolerance to allografts is already known. Studies by our group have shown that the PD1/PDL1 pathway also plays an important 
role in the maintenance of tolerance to the fetus.

A study by Guleria et al. reported that the blockade of PD1/PDL1 pathway results in fetal loss in allogeneic mouse model of pregnancy, and the involvement of PD1/PDL1 pathway in feto-maternal tolerance. ${ }^{[43]}$ The effect of anti-PDL1 treatment is mediated through the maternal $\mathrm{T}$ cell population that is alloreactive and secretes high amounts of IFN- $\gamma$.

Another study by our group provides evidence of a link between PD1/PDL1 pathway and Tregs in promoting tolerance at the FMI. In continuation of their previous observations that abrogation of tolerance at the FMI by PDL1 blockade is mediated through the maternal T cells, Habicht et al. provided further evidence that PDL1 blockade results in functionally deficient Tregs. ${ }^{[46]}$

The above observations suggest an indirect effect of PDL1 blockade on alloreactive maternal T cells which is mediated through Tregs that are rendered inefficient and unable to regulate the tolerance mechanism at the FMI. Blockade of PDL1 also results in excessive inflammation, observed by high IFN- $\gamma$ production, creating a pro-inflammatory environment conducive to Th1/Th17 effector $\mathrm{T}$ cell induction and proliferation.

D'Addio et al. reported that PDL1 blockade results in a shift in the Th balance more toward a Th17 type at the FMI. However, they did not observe a conversion of Tregs to Th17 phenotype following anti-PDL1 treatment; rather, they saw an increase in IL-17 producing $\mathrm{CD}^{+}{ }^{+} \mathrm{Foxp}^{-}$cells and also a decrease in conversion of $\mathrm{CD}^{+}{ }^{+}$Foxp $3^{-}$cells into $\mathrm{CD}^{+}{ }^{+}$Foxp $3^{+}$cell type ${ }^{[79]}$ Figure 1 illustrates the interaction between Treg and Th17 cells.

Again these observations suggest an indirect effect of PDL1 blockade on effector T cells that is mediated by the functionally defective Treg population.

In another similar study, blockade of PD1 is reported to abrogate the protective effect of Tregs in an abortion prone $\mathrm{CBA} \times$ DBA mouse model of allogeneic pregnancy ${ }^{[42]}$ PD1 is also reported to regulate the abundance of antigen-specific maternal T cells during pregnancy. PD1 is upregulated by the maternal $\mathrm{T}$ cells during gestation and in the absence of PD1 paternal antigen-specific maternal CD8+ T cells accumulate in the uterine draining lymph nodes in large numbers. This phenomenon is due to decrease in the rate of apoptosis of these cells. ${ }^{[80]}$ In another study, PD1 blockade was found to be associated with increased $\mathrm{T}$ cell proliferation in the spleen. In the uterus draining lymph nodes, proliferation is limited to only the CD4+ T cells following PD1 blockade, whereas in the uterus, the T cell pool is completely altered, and the authors suggest that PD1 plays a role in regulating the dynamic $\mathrm{T}$ cell homeostasis in the uterus during pregnancy. ${ }^{[81]}$

These studies provide direct evidence that the PD1/PDL1 pathway plays an important role in fetal pro- tection. Blockade of this pathway, by either anti-PD1 or anti-PDL1, results in diminished Treg function, increased $\mathrm{T}$ cell accumulation and proliferation, dysregulated $\mathrm{T}$ cell homeostasis, and abrogates the fine balance of tolerance and immunity at the FMI.

\section{Crosstalk between the PDL1, Th17, and Tregs at the FMI}

The recent understanding in Treg plasticity and their conversion to Th17-type cells under certain inflammatory cytokine polarizing conditions are of interest in feto-maternal tolerance due to the unique and transient nature of inflammation associated with gestation. The plasticity of the Th cell population, specifically conversion between the $T$ regulatory and the Th17 phenotype, may explain the regulation of $\mathrm{T}$ cell tolerance at the FMI. The PD1/PDL1 pathway plays an important role in this mix, as it directly affects the suppressive properties of the Treg population ${ }^{[46]}$ as well as abrogates the protective effects of Treg treatment. ${ }^{[42]}$ Blockade of PD1/ PDL1 pathway also prevents the conversion of naïve Th cells to a Treg phenotype, ${ }^{[79]}$ thereby creating a bias toward an inflammatory environment that is conducive for the survival and expansion of both Th1 and Th17 types of cell populations. Th17 cells are involved in fetal loss, as discussed earlier in this article, by creating an excessive inflammatory microenvironment at the FMI. There is also another additional risk of Th17/Th1 plasticity that has the potential to prolong the transient inflammatory microenvironment at the FMI that we have not summarized here. Transient inflammation is good and necessary in early gestation, and excessive and prolong inflammation at the later stages of gestation is regulated by the anti-inflammatory cytokines secreted by the trophoblast at the local site and the Tregs to prevent fetal loss by the maternal effector T cells. The role of PD1/PDL1 pathway comes to play in maintaining this homeostasis between Tregs, Th17, and Th1 cells, thereby regulating tolerance at the FMI.

The PD1/PDL1 pathway may contribute to the regulation of tolerance at the FMI through multiple mechanisms. (1) The PD1/PDL1 pathway probably regulates the induction and differentiation of the uncommitted helper $\mathrm{T}$ cells into a paternal antigen-specific Treg phenotype, as it is already reported that $\mathrm{T}$ cell awareness to paternal antigens exists and paternal antigen-specific Tregs are detected in the decidua. (2) An inverse correlation is observed between the proportion of Th17 cells and Tregs in pregnancy, and PD1/PDL1 pathway might also play a role in maintaining the ratio of the Th17/Tregs at the FMI as blockade of the pathway results in an increase in the IL-17 producing cells. (3) The PD1/PDL1 pathway also regulates the suppressive activity of the Tregs and, thus, indirectly regulates the effector $\mathrm{T}$ cell population at the FMI and maintains a tolerant environment. It is already known that the PD1/PDL1 pathway is involved in the con- 


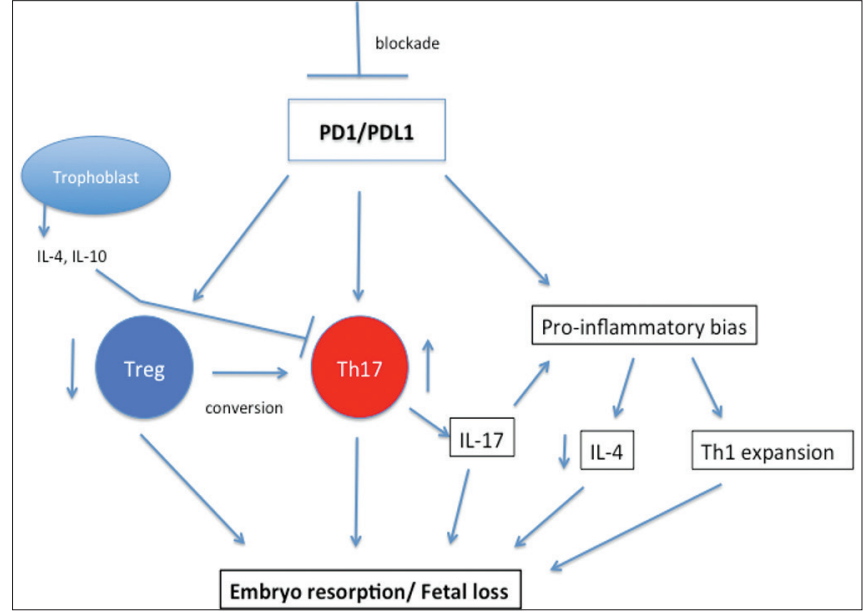

Figure 1: Blockade of PD1/PDL1 pathway may result in a decrease in the efficiency of Tregs and an increase in inflammatory Th17 cells leading to loss of tolerance at the FMI.

version of Th1 cells to Tregs ${ }^{[78]}$ Figure 1 depicts possible mechanism of PD1-PDL1 induced tolerance at the FMI.

There are a number of reports that provide evidence of PD1/PDL1 pathway controlling the Th17 cell population in various other diseases in humans and also in different mice models. Dulos et al. reported that blockade of PD1/PDL1 pathway in patients with cancer leads to a Th1/Th17 type of cellular response accompanied with increased IL-17 production. ${ }^{[82]}$ In another study, Rui et al. provided evidence of increased differentiation and production of antigen-specific Th17 cells in PD1-knockout mice. ${ }^{[83]}$ A large number of studies, mostly in the context of cancer immunotherapy, report that the blockade of PD1/PDL1 pathway leads to an increase in effector $\mathrm{T}$ cell response with a proinflammatory Th1/Th17 bias and decrease in Treg efficiency and percentage in the tumor microenvironment. At present, blockade of the PD1/PDL1 pathway is also under consideration as an effective cancer immunotherapy.

Considering all the current evidences, it is needless to say that PD1/PDL1 pathway is an important regulator of the Treg and Th17 balance in many different disease conditions and also plays a significant role in maintaining the fine balance between tolerance and immunity at the FMI. The question that remains to be answered is if the PD1/PDL1 pathway plays a direct role in the regulation of tolerance by preventing conversion of Tregs to Th17 cells in the decidua or maintains the homeostasis between the Tregs and Th17 cells at the FMI and indirectly maintains the tolerance.

\section{REFERENCES}

1. Zourbas S, Dubanchet S, Martal J, Chaouat G. Localization of pro-inflammatory (IL-12, IL-15) and anti-inflammatory (IL-11, IL-13) cytokines at the foetomaternal interface during murine pregnancy. Clin Exp Immunol 2001;126:519-28.
2. Blois SM, Joachim R, Kandil J, Margni R, Tometten M, Klapp BF, Arck PC. Depletion of CD $8+$ cells abolishes the pregnancy protective effect of progesterone substitution with dydrogesterone in mice by altering the Th1/Th2 cytokine profile. J Immunol 2004;172:5893-9.

3. Lin H, Mosmann TR, Guilbert L, Tuntipopipat S, Wegmann TG. Synthesis of Thelper 2-type cytokines at the maternal-fetal interface. J Immunol 1993;151:4562-73.

4. Piccinni MP. T cell tolerance towards the fetal allograft. J Reprod Immunol 2010;85:71-5.

5. Blois SM, Klapp BF, Barrientos G. Decidualization and angiogenesis in early pregnancy: Unravelling the functions of DC and NK cells. J Reprod Immunol 2011;88:86-92.

6. Wilczynski JR. Th1/Th2 cytokines balance--yin and yang of reproductive immunology. Eur J Obstet Gynecol Reprod Biol 2005;122:136-43.

7. Saito S, Nakashima A, Shima T, Ito M. Th1/Th2/Th17 and regulatory T-cell paradigm in pregnancy. Am J Reprod Immunol 2010;63:601-10.

8. Guleria I, Sayegh MH. Maternal acceptance of the fetus: True human tolerance. J Immunol 2007;178:3345-51.

9. Riley JK. Trophoblast immune receptors in maternal-fetal tolerance. Immunol Invest 2008;37:395-426.

10. Clark DA, Chaouat G, Wong K, Gorczynski RM, Kinsky R. Tolerance mechanisms in pregnancy: A reappraisal of the role of class I paternal MHC antigens. Am J Reprod Immunol 2010;63:93-103.

11. Leber A, Zenclussen ML, Teles A, Brachwitz N, Casalis P, El-Mousleh T, et al. Pregnancy: Tolerance and suppression of immune responses. Methods Mol Biol 2011;677:397-417.

12. Oreshkova T, Dimitrov R, Mourdjeva M. A cross-talk of decidual stromal cells, trophoblast, and immune cells: A prerequisite for the success of pregnancy. Am J Reprod Immunol 2012;68:366-73.

13. Raulet DH. Missing self recognition and self tolerance of natural killer (NK) cells. Semin Immunol 2006;18:145-50.

14. Raulet DH, Held W, Correa I, Dorfman JR, Wu MF, Corral L. Specificity, tolerance and developmental regulation of natural killer cells defined by expression of class I-specific Ly49 receptors. Immunol Rev 1997;155:41-52.

15. Apps R, Gardner L, Moffett A. A critical look at HLA-G. Trends Immunol 2008;29:313-21.

16. Miwa N, Hayakawa S, Miyazaki S, Myojo S, Sasaki Y, Sakai M, et al. IDO expression on decidual and peripheral blood dendritic cells and monocytes/macrophages after treatment with CTLA-4 or interferon-gamma increase in normal pregnancy but decrease in spontaneous abortion. Mol Hum Reprod 2005;11:865-70.

17. AlokA, KarandeAA. The role of glycodelin as an immune-modulating agent at the feto-maternal interface. J Reprod Immunol 2009;83:124-7.

18. Lee CL, Chiu PC, Lam KK, Siu SO, Chu IK, Koistinen R, et al. Differential actions of glycodelin-A on Th-1 and Th-2 cells: A paracrine mechanism that could produce the Th-2 dominant environment during pregnancy. Hum Reprod 2011;26:517-26.

19. Scholz C, Toth B, Brunnhuber R, Rampf E, Weissenbacher T, Santoso L, et al. Glycodelin A induces a tolerogenic phenotype in monocyte-derived dendritic cells in vitro. Am J Reprod Immunol 2008;60:501-12.

20. Kauma SW, Huff TF, Hayes N, Nilkaeo A. Placental Fas ligand 
expression is a mechanism for maternal immune tolerance to the fetus. J Clin Endocrinol Metab 1999;84:2188-94.

21. Uckan D, Steele A, Cherry, Wang BY, Chamizo W, Koutsonikolis A, et al. Trophoblasts express Fas ligand: A proposed mechanism for immune privilege in placenta and maternal invasion. Mol Hum Reprod 1997;3:655-62.

22. Jiang SP, Vacchio MS. Multiple mechanisms of peripheral $\mathrm{T}$ cell tolerance to the fetal "allograft". J Immunol 1998;160:3086-90.

23. Hammer A, Blaschitz A, Daxbock C, Walcher W, Dohr G. Fas and Fas-ligand are expressed in the uteroplacental unit of first-trimester pregnancy. Am J Reprod Immunol 1999;41:41-51.

24. Eide IP, Isaksen CV, Salvesen KA, Langaas M, Gunther CC, Iversen $\mathrm{AC}$, et al. Fetal growth restriction is associated with reduced FasL expression by decidual cells. J Reprod Immunol 2007;74:7-14.

25. Hunt JS, Vassmer D, Ferguson TA, Miller L. Fas ligand is positioned in mouse uterus and placenta to prevent trafficking of activated leukocytes between the mother and the conceptus. J Immunol 1997; 158:4122-8.

26. Vacchio MS, Hodes RJ. Fetal expression of Fas ligand is necessary and sufficient for induction of CD8 $\mathrm{T}$ cell tolerance to the fetal antigen H-Y during pregnancy. J Immunol 2005;174:4657-61.

27. Sacks G, Sargent I, Redman C. An innate view of human pregnancy. Immunol Today 1999;20:114-8.

28. Tafuri A, Alferink J, Moller P, Hammerling GJ, Arnold B. T cell awareness of paternal alloantigens during pregnancy. Science $1995 ; 270: 630-3$

29. Clark DA, Slapsys R, Croy BA, Krcek J, Rossant J. Local active suppression by suppressor cells in the decidua: A review. Am J Reprod Immunol 1984;5:78-83.

30. Sasaki Y, Sakai M, Miyazaki S, Higuma S, Shiozaki A, Saito S. Decidual and peripheral blood $\mathrm{CD} 4+\mathrm{CD} 25+$ regulatory $\mathrm{T}$ cells in early pregnancy subjects and spontaneous abortion cases. Mol Hum Reprod 2004;10:347-53.

31. Aluvihare VR, Kallikourdis M, Betz AG. Regulatory T cells mediate maternal tolerance to the fetus. Nat Immunol 2004;5:266-71.

32. Zenclussen AC, Gerlof K, Zenclussen ML, Sollwedel A, Bertoja AZ, Ritter T, et al. Abnormal T-cell reactivity against paternal antigens in spontaneous abortion: Adoptive transfer of pregnancy-induced CD4+CD25+ T regulatory cells prevents fetal rejection in a murine abortion model. Am J Pathol 2005;166:811-22.

33. Somerset DA, Zheng Y, Kilby MD, Sansom DM, Drayson MT. Normal human pregnancy is associated with an elevation in the immune suppressive CD25+CD4+ regulatory T-cell subset. Immunology 2004;112:38-43.

34. Wegienka G, Havstad S, Bobbitt KR, Woodcroft KJ, Zoratti EM, Ownby DR, et al. Within-woman change in regulatory T cells from pregnancy to the postpartum period. J Reprod Immunol 2010;88:58-65.

35. Ait-Azzouzene D, Gendron MC, Houdayer M, Langkopf A, Burki K, Nemazee D, et al. Maternal B lymphocytes specific for paternal histocompatibility antigens are partially deleted during pregnancy. J Immunol 1998;161:2677-83.

36. Ait-Azzouzene D, Caucheteux S, Tchang F, Wantyghem J, Moutier R, Langkopf A, et al. Transgenic major histocompatibility complex class I antigen expressed in mouse trophoblast affects maternal immature B cells. Biol Reprod 2001;65:337-44.

37. Samsami Dehaghani A, Doroudchi M, Kalantari T, Pezeshki AM,
Ghaderi A. Heterozygosity in CTLA-4 gene and severe preeclampsia. Int J Gynaecol Obstet 2005;88:19-24

38. Ruter J, Hoffmann T, Heiser U, Demuth HU, Arck PC, Klapp BF, et al. The expression of T-cell surface antigens CTLA-4, CD26, and CD28 is modulated by inhibition of dipeptidylpeptidase IV (DPP IV, CD26) activity in murine stress-induced abortions. Cell Immunol 2002;220:150-6.

39. Jin LP, Chen QY, Zhang T, Guo PF, Li DJ. The CD4+ CD25 bright regulatory T cells and CTLA-4 expression in peripheral and decidual lymphocytes are down-regulated in human miscarriage. Clin Immunol 2009;133:402-10.

40. Wang X, Ma Z, Hong Y, Lu P, Lin Q. Expression of CD28 and cytotoxic $\mathrm{T}$ lymphocyte antigen 4 at the maternal-fetal interface in women with unexplained pregnancy loss. Int J Gynaecol Obstet 2006;93:123-9.

41. Jin LP, Zhou YH, Wang MY, Zhu XY, Li DJ. Blockade of CD80 and CD86 at the time of implantation inhibits maternal rejection to the allogeneic fetus in abortion-prone matings. J Reprod Immunol 2005;65:133-46.

42. Wafula PO, Teles A, Schumacher A, Pohl K, Yagita H, Volk HD, et al. PD-1 but not CTLA-4 blockage abrogates the protective effect of regulatory $\mathrm{T}$ cells in a pregnancy murine model. Am J Reprod Immunol 2009;62:283-92.

43. Guleria I, Khosroshahi A, Ansari MJ, Habicht A, Azuma M, Yagita H, et al. A critical role for the programmed death ligand 1 in fetomaternal tolerance. J Exp Med 2005;202:231-7.

44. Jin LP, Fan DX, Li DJ. Regulation of costimulatory signal in maternal-fetal immune tolerance. Am J Reprod Immunol 2011;66:76-83.

45. Okazaki T, Honjo T. The PD-1-PD-L pathway in immunological tolerance. Trends Immunol 2006;27:195-201.

46. Habicht A, Dada S, Jurewicz M, Fife BT, Yagita H, Azuma M, et al. A link between PDL1 and T regulatory cells in fetomaternal tolerance. J Immunol 2007;179:5211-9.

47. Riella LV, Dada S, Chabtini L, Smith B, Huang L, Dakle P, et al. B7h (ICOS-L) maintains tolerance at the fetomaternal interface. Am J Pathol 2013;182:2204-13.

48. Petroff MG, Perchellet A. B7 family molecules as regulators of the maternal immune system in pregnancy. Am J Reprod Immunol 2010;63:506-19.

49. Krey G, Frank P, Shaikly V, Barrientos G, Cordo-Russo R, Ringel F, et al. In vivo dendritic cell depletion reduces breeding efficiency, affecting implantation and early placental development in mice. J Mol Med (Berl) 2008;86:999-1011.

50. Plaks V, Birnberg T, Berkutzki T, Sela S, BenYashar A, Kalchenko V, et al. Uterine DCs are crucial for decidua formation during embryo implantation in mice. J Clin Invest 2008;118:3954-65.

51. Nagamatsu T, Schust DJ. The contribution of macrophages to normal and pathological pregnancies. Am J Reprod Immunol 2010;63:460-71

52. Vacca P, Mingari MC, Moretta L. Natural killer cells in human pregnancy. J Reprod Immunol 2013;97:14-9.

53. Heikkinen J, Mottonen M, Alanen A, Lassila O. Phenotypic characterization of regulatory $\mathrm{T}$ cells in the human decidua. Clin Exp Immunol 2004;136:373-8.

54. Saito S, Sasaki Y, Sakai M. CD4(+) CD25high regulatory T cells in

Biomed J Vol. 38 No. 1

January - February 2015 
human pregnancy. J Reprod Immunol 2005;65:111-20.

55. Zhao JX, Zeng YY, Liu Y. Fetal alloantigen is responsible for the expansion of the CD4(+) CD25(+) regulatory $\mathrm{T}$ cell pool during pregnancy. J Reprod Immunol 2007;75:71-81.

56. Kahn DA, Baltimore D. Pregnancy induces a fetal antigen-specific maternal T regulatory cell response that contributes to tolerance. Proc Natl Acad Sci U S A 2010;107:9299-304.

57. Shima T, Sasaki Y, Itoh M, Nakashima A, Ishii N, Sugamura K, et al. Regulatory $\mathrm{T}$ cells are necessary for implantation and maintenance of early pregnancy but not late pregnancy in allogeneic mice. J Reprod Immunol 2010;85:121-9.

58. Yin Y, Han X, Shi Q, Zhao Y, He Y. Adoptive transfer of $\mathrm{CD} 4+\mathrm{CD} 25+$ regulatory $\mathrm{T}$ cells for prevention and treatment of spontaneous abortion. Eur J Obstet Gynecol Reprod Biol 2012;161:177-81.

59. Darrasse-Jeze G, Klatzmann D, Charlotte F, Salomon BL, Cohen JL. $\mathrm{CD} 4+\mathrm{CD} 25+$ regulatory/suppressor $\mathrm{T}$ cells prevent allogeneic fetus rejection in mice. Immunol Lett 2006;102:106-9.

60. Robertson SA, Guerin LR, Bromfield JJ, Branson KM, Ahlstrom $\mathrm{AC}$, Care AS. Seminal fluid drives expansion of the CD4+CD25+ T regulatory cell pool and induces tolerance to paternal alloantigens in mice. Biol Reprod 2009;80:1036-45.

61. Shima T. Paternal antigen-specific regulatory T cells proliferate in the draining lymph nodes before the implantation and proliferate in the uterus after the implantation, and are necessary for maintenance of allogeneic pregnancy. 2010 ASRI Annual Meeting Abstract 2010.

62. Schumacher A, Brachwitz N, Sohr S, Engeland K, Langwisch S, Dolaptchieva $\mathrm{M}$, et al. Human chorionic gonadotropin attracts regulatory $\mathrm{T}$ cells into the fetal-maternal interface during early human pregnancy. J Immunol 2009;182:5488-97.

63. Jasper MJ, Tremellen KP, Robertson SA. Primary unexplained infertility is associated with reduced expression of the T-regulatory cell transcription factor Foxp3 in endometrial tissue. Mol Hum Reprod 2006;12:301-8.

64. Yang H, Qiu L, Chen G, Ye Z, Lu C, Lin Q. Proportional change of $\mathrm{CD} 4+\mathrm{CD} 25+$ regulatory $\mathrm{T}$ cells in decidua and peripheral blood in unexplained recurrent spontaneous abortion patients. Fertil Steril 2008;89:656-61.

65. Mei S, Tan J, Chen H, Chen Y, Zhang J. Changes of CD4 + CD25high regulatory T cells and FOXP3 expression in unexplained recurrent spontaneous abortion patients. Fertil Steril 2010;94:2244-7.

66. Hao K, Zhou Q, Chen W, Jia W, Zheng J, Kang J, et al. Possible role of the 'IDO-AhR axis' in maternal-foetal tolerance. Cell Biol Int 2013;37:105-8.

67. Teles A, Zenclussen AC, Schumacher A. Regulatory T cells are baby's best friends. Am J Reprod Immunol 2013;69:331-9.

68. Rowe JH, Ertelt JM, Xin L, Way SS. Pregnancy imprints regulatory memory that sustains anergy to fetal antigen. Nature 2012;490:102-6.
69. Rowe JH, Ertelt JM, Xin L, Way SS. Listeria monocytogenes cytoplasmic entry induces fetal wastage by disrupting maternal Foxp3+ regulatory T cell-sustained fetal tolerance. PLoS Pathog 2012;8:e1002873.

70. Mjosberg J, Berg G, Jenmalm MC, Ernerudh J. FOXP3+ regulatory $\mathrm{T}$ cells and $\mathrm{T}$ helper $1, \mathrm{~T}$ helper 2 , and $\mathrm{T}$ helper 17 cells in human early pregnancy decidua. Biol Reprod 2009;82:698-705.

71. Wang WJ, Hao CF, Qu QL, Wang X, Qiu LH, Lin QD. The deregulation of regulatory $\mathrm{T}$ cells on interleukin-17-producing $\mathrm{T}$ helper cells in patients with unexplained early recurrent miscarriage. Hum Reprod 2010;25:2591-6.

72. Wang WJ, Hao CF, Yi-Lin, Yin GJ, Bao SH, Qiu LH, et al. Increased prevalence of Thelper 17 (Th17) cells in peripheral blood and decidua in unexplained recurrent spontaneous abortion patients. J Reprod Immunol 2010;84:164-70.

73. Liu F, Guo J, Tian T, Wang H, Dong F, Huang H, et al. Placental trophoblasts shifted Th1/Th2 balance toward Th2 and inhibited Th17 immunity at fetomaternal interface. APMIS 2011;119:597-604.

74. Wang WJ, Liu FJ, Xin-Liu, Hao CF, Bao HC, Qu QL, et al. Adoptive transfer of pregnancy-induced $\mathrm{CD} 4+\mathrm{CD} 25+$ regulatory $\mathrm{T}$ cells reverses the increase in abortion rate caused by interleukin 17 in the CBA/JxBALB/c mouse model. Hum Reprod 2014;29:946-52.

75. Leung S, Liu X, Fang L, Chen X, Guo T, Zhang J. The cytokine milieu in the interplay of pathogenic Th1/Th17 cells and regulatory T cells in autoimmune disease. Cell Mol Immunol 2010;7:182-9.

76. Kimura A, Kishimoto T. IL-6: Regulator of Treg/Th17 balance. Eur J Immunol 2010;40:1830-5.

77. Cooney LA, Fox DA. Regulation of Th17 maturation by interleukin 4. Crit Rev Immunol 2013;33:379-87.

78. Amarnath S, Mangus CW, Wang JC, Wei F, He A, Kapoor V, et al. The PDL1-PD1 axis converts human TH1 cells into regulatory T cells. Sci Transl Med 2011;3:111ra20.

79. D'Addio F, Riella LV, Mfarrej BG, Chabtini L, Adams LT, Yeung M, et al. The link between the PDL1 costimulatory pathway and Th17 in fetomaternal tolerance. J Immunol 2011;187:4530-41.

80. Taglauer ES, Yankee TM, Petroff MG. Maternal PD-1 regulates accumulation of fetal antigen-specific CD8+ T cells in pregnancy. J Reprod Immunol 2009;80:12-21.

81. Shepard MT, Bonney EA. PD-1 regulates T cell proliferation in a tissue and subset-specific manner during normal mouse pregnancy. Immunol Invest 2013;42:385-408.

82. Dulos J, Carven GJ, van Boxtel SJ, Evers S, Driessen-Engels LJ, Hobo W, et al. PD-1 blockade augments Th1 and Th17 and suppresses Th2 responses in peripheral blood from patients with prostate and advanced melanoma cancer. J Immunother 2012;35:169-78.

83. Rui Y, Honjo T, Chikuma S. Programmed cell death 1 inhibits inflammatory helper T-cell development through controlling the innate immune response. Proc Natl Acad Sci U S A 2013;110:16073-8. 